\title{
Involving Students in the Instructional Design Process to Improve Their Satisfaction with Their Learning in the COVID-19 Era
}

\author{
Ryane Imane
}

\begin{abstract}
Like most university students worldwide, the engineering students at the School of Information Sciences (ESI) have to deal with their school closure and the new paradigm of distance learning. Despite efforts made by the administration and the teachers to accompany students, an internal survey conducted by the end of October 2021 revealed that almost all students, especially first-year ones, did not accept distance learning. This paper describes our experience to improve students' satisfaction with distance learning by involving them in their courses' design process. Four courses were concerned by the experience and were designed following the ADDIE method. Last-year students participated in the ADDIE analysis step, while the first-year students participated in the last step by evaluating the co-created courses. Courses were co-created with students as most of them got involved in the ADDIE development step and enriched courses by realizing extras activities. Results showed that students were highly satisfied with courses taught in the context of this study.
\end{abstract}

Index Terms-COVID-19, ADDIE, Moodle, MS teams, engineering education.

\section{INTRODUCTION}

The COVID-19 pandemic has changed how we work, learn, eat and chill out [1]. It is still changing every single action in our daily life. In Morocco, a national lockdown was decided to stop the spread of the COVID-19 virus. The lockdown started in March 2020 and lasted for three months. Naturally, education has been hugely impacted. Like many other universities worldwide [2], our engineering school ESI switched to full-distance learning during the COVID-19 lockdown. ESI or school of information science is an engineering public school located in Rabat, Morocco's capital. Since the COVID-19 situation in Morocco did not improve by September 2020, with almost three thousand new positive cases and fifty deaths per day [3], the ESI school has continued full distance learning for the first semester 2020-21.

As organizational commitment is the most important key success factor in e-learning implementation [4], the ESI school administration was invested in providing students and teachers with the necessary tools to continue learning in good conditions. Two learning media were adopted: an LMS (Moodle) and a video conferencing system (MS Teams). The LMS availability is also an important aspect [5], so

Manuscript received March 12, 2021; revised May 30, 2021.

The author is with the School of Information Sciences, Morocco (e-mail: iryane@esi.ac.ma). corrections were made to Moodle LMS to deal with the poor performance issues faced by students during the COVID-19 national lockdown. Most of the professors are IT experts, so they quickly got familiar with remote teaching. One can think that the different stakeholders' efforts were sufficient to guarantee students' satisfaction with distance learning. To verify this hypothesis, an internal survey was conducted by the end of October 2021. The survey revealed an alarming finding concerning students' position regarding distance learning. Most of the students from the three levels did not agree with distance learning. The first-year ones were particularly reluctant to distance learning with an acceptance rate of only $29.4 \%$.

Going to university, for most students is the beginning of their new lives as adults. Before the COVID-19 crisis, students moved from other cities to Rabat to join the ESI school. They became independent from their families and had to manage themselves their daily life. The school was also a place to meet new friends and organize sport, cultural and professional events. Due to social distancing measures, students had to stay with their families, and the school's role was reduced to a learning content provider. As younger people are more vulnerable to mental health problems due to social distancing measures than adults [6], many studies reported problems affecting students' mental health and younger people. In specific, Loades et al. [7] noticed an important risk of developing stress, depression, and anxiety disorders during lockdowns. Cao et al. [8] discovered that students were highly anxious about the impact of the COVID-19 pandemic on their academic achievement. Finally, Karasmanaki et al. [9] founded that anger is the most negative emotion experienced by students. This is mainly caused by the closure of universities and the requirement to attend all courses online.

The ESI students found it difficult to adjust to this new learning paradigm. As mentioned before, only $29.4 \%$ of first-year students agreed with distance learning. The idea behind the current study is to involve students in the courses as peers to improve their distance learning satisfaction. Four courses were concerned: two intended for last-year students and two for first-year ones. Courses were designed according to the ADDIE method. Students got involved in most of the design process. They participated in the analysis, development, and evaluation of their courses. The paper is divided into three parts. It starts with a literature review where key concepts of the study are defined. In the second part, the adopted methodology is presented in detail. In the end, the most important findings are analyzed. 


\section{LITERATURE REVIEW}

\section{A. Instructional Engineering}

Instructional engineering is the branch of engineering that studies learning systems. More precisely, instructional engineering is "a method that supports the analysis, the design and the delivery planning of a learning system, integrating the concepts, the processes and the principles of instructional design, software engineering and cognitive engineering" [10]. Therefore, instructional engineering is based on three areas: software engineering, cognitive engineering, and finally the instructional design. We tend to confuse instructional engineering with instructional design. Berger et al. [11] define instructional design as "the systematic development of instructional specifications using learning and instructional theory to ensure instruction quality. It is the entire process of analysis of learning needs and goals and developing a delivery system to meet those needs. It includes the development of instructional materials and activities; and tryout and evaluation of all instruction and learner activities". The instructional design is a process that takes as input the learning objectives and leads to a modelization of the learning system in terms of activities and learning content. According to these definitions, the two concepts of instructional design and instructional engineering are different: the instructional design focuses on the pedagogical aspect in a training project, while instructional engineering is a broader approach that studies the training project from other perspectives than pedagogy.

\section{B. ADDIE}

Several models exist to describe the process of instructional engineering. In this paper, we used the classical ADDIE (Analysis Design Development Implementation Evaluation) model [12]. ADDIE model is like the software development life cycle (Fig. 1). It helps to identify different problems that one should solve before developing the learning system. It seems to be time-consuming but guarantees to deliver a high-quality learning system.

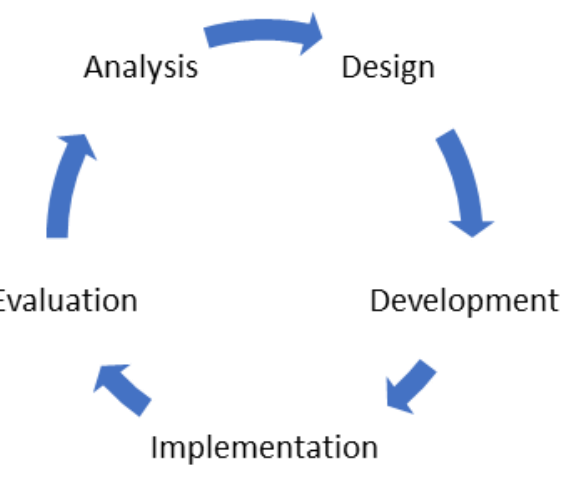

Fig. 1. The 5-stages of the ADDIE model.

Der Sahakian et al. [13] describe the five steps of the ADDIE model:

- Analysis: In this step, we study all the parameters that can influence the training project. For example, the learning needs, the learner's characteristics, the training context, and the existing resources.

- Design: This step aims to draw up specifications from the data collected in the analysis step. The specifications define the learning objectives, the instructional strategies, and the learning media used for the training.

- Development: It is the construction or the realization of the learning system. However, before starting the development, one should create a learning scenario. Known by different names such as pedagogical sequence, lesson plan, or storyboard, the learning scenario is an important artifact in the ADDIE model. It allows describing, for a given learning situation, the learning and the support activities, the roles, the target audience, the prerequisites, the learning objectives, and the tools necessary for the realization of activities [14]. Constructing learning scenarios aims to plan learning situations better and improve learners' learning [15], [16].

- Implementation: During this step, the learning system is made available to learners, for example, by using an LMS (Learning Management System).

- Evaluation: This is the last stage of the process, where the learning system is evaluated. This stage aims to detect problems to solve, but also weaknesses to improve.

\section{Flipped Classroom}

The flipped classroom (FL) is an instructional strategy that is increasingly adopted in different disciplines and all education levels [17]. It aims to place the learner in the center of the learning process. Unlike the traditional teaching methods, FL pushes learners to be more responsible for their learning and more active while constructing it. In FL, the learning experience starts before the in-class session. Indeed, the teacher proposes online learning resources that explain topics treated in the course. The in-class session is then used to clarify unclear parts in the online resources and engage students in more complex activities. the FL approach helps the teacher play the facilitator of learning as the activities proposed in the in-class sessions tend to be collaborative and peer-learning oriented (Fig. 2). He acts as a "guide on the side" [18] ready to help in case of difficulties.

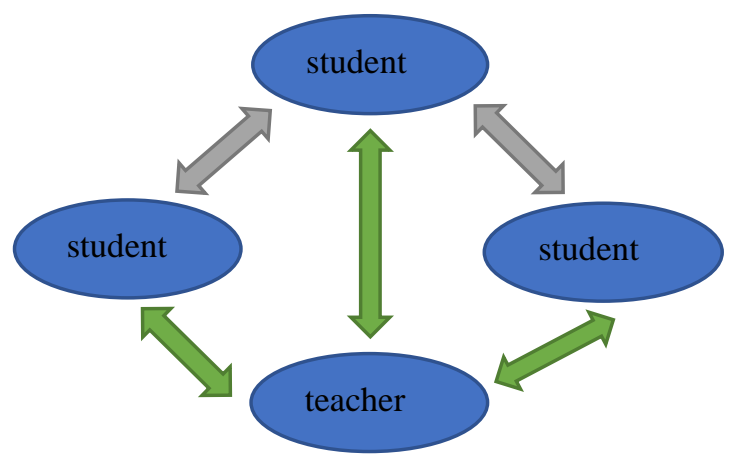

Fig. 2. Interactions in flipped classroom.

Several studies showed the effectiveness of the FL approach in many areas. We outlined below the most important outcomes of applying FL in the higher education context:

- Achieving effective learning in large classrooms [19].

- Students can learn at their own pace, and teachers have more flexibility in delivering their courses [20].

- Improving lab practice results of students in technical degree courses [21].

- Enhancing equity among students [22]. Fiske and Ladd 
define equity as providing students equal treatment, equal educational opportunity, and educational adequacy to evaluate their progress in the learning environments toward achieving their instructional goals [23].

\section{Methodology AND IMPLEMENTATION}

An internal survey conducted by the end of October 2021 revealed that most ESI school students disagreed with distance learning. They were only $29.4 \%$ in the first level who accept to learn online. These survey findings were the starting point of this research.

In the first semester of the academic year 2020-21, the author had to teach four courses. Two courses intended for last-year students: distributed systems and embedded systems. The other two courses are reserved for first-year students: assembly language and operating systems. All courses had to be delivered online because of the COVID-19 crisis. The courses were designed according to the ADDIE method. Students got involved in most of the design process. They participated in the analysis, development, and evaluation of their courses. The reason behind our choice is to enhance their satisfaction with their learning experience as most of them did not like to learn online. The last-year students participated in the analysis step because they have experienced distance learning since the COVID-19 lockdown. So, they can bring out much more issues and challenges. In the evaluation step, first-year students were invited to complete a satisfaction survey about the courses taught by the author. We chose first-year students because they did not have any previous experience in distance learning that could bias their judgments. Finally, we proposed some extras activities that enabled students to participate in the development stage.

\section{A. Analysis}

In this first step, learning needs, learner's characteristics, and the context of training should be identified. As it was the author's first experience in teaching, in a full distance model, data should be collected about the conditions, where learning has taken place. To better understand the constraints that students have to face in the full distance model, we conducted an anonymous survey. The survey concerned the last-year students. Forty-one students answered the survey. The participation rate was $75 \%$ for females, and $78 \%$ for male students. We proposed twenty-two questions: eighteen closed-ended and four open-ended.

When we asked students if they have the prerequisites (computer \& Internet) to take the course online, 27\% of them confirmed their lack of the necessary equipment to take the online course in good conditions (Fig. 3). Analysis of the open-ended questions gave more details about this result and showed that students almost used old computers and struggled with internet access issues. These problems also explained why $41 \%$ of students found online sessions more stressful than in-class ones (Fig. 4) and 46\% of them couldn't stay focused during online sessions (Fig. 5).

Most of the students still missing the class atmosphere and outlined it as the main disadvantage of distance learning (Fig. 6). Only $44 \%$ of them can interact with each other like in-class sessions (Fig. 7). They also suggested using group projects for learning (Fig. 8) and individual project for assessment (Fig. 9).

Q: Do you have the prerequisites (computer \& Internet) to take the course online?

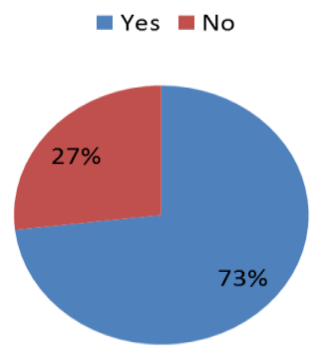

Fig. 3. Percentage of students facing technical issues.

Q: The online sessions are more stressful than in-class sessions?

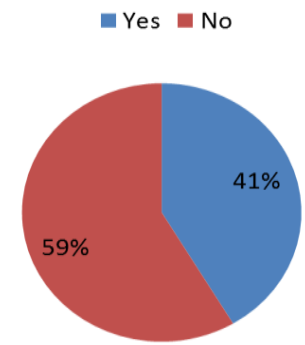

Fig. 4. Percentage of students stressed by online sessions.

Q: Is it difficult for you to stay focused in online session?

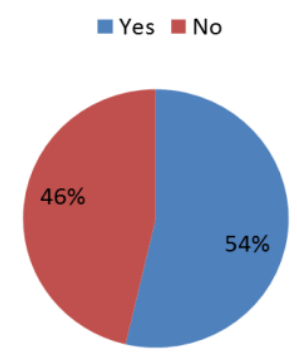

Fig. 5. Percentage of students having trouble focusing during online sessions.

Q: The main disadvantage of distance learning is:

- Important workload

I I miss the class atmosphere

n Teacher doesn't give me the necessary support

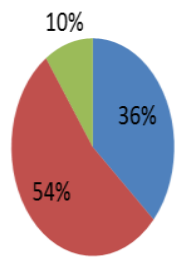

Fig. 6. Students' feedback about some disadvantages of distance learning.

Q: Can you interact with your classmates as you did in in-class sessions?

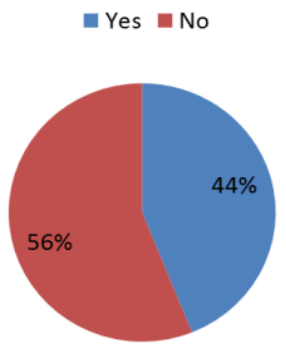

Fig. 7. Percentage of students that can interact remotly with their peers as they did in in-class sessions. 
Q: To develop practical skills, which learning method do you prefer most?
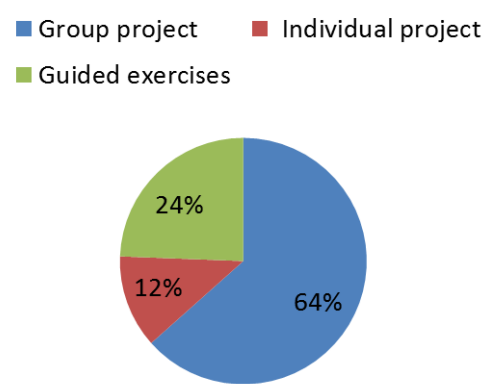

Fig. 8. Students' preferences regarding learning activities.

Q: To assess practical skills, which learning method do you prefer most?

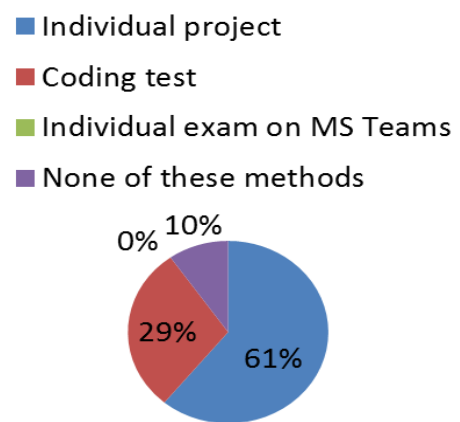

Fig. 9. Students' preferences regarding assessment activities.

\section{B. Design}

The analysis step was helpful as it showed us the reality of distance learning for students. We retain that:

- Technical issues should be taken into consideration while designing the course,

- Although peers' interactions are important, distance learning did not facilitate them,

- Project-based learning is the most preferred learning strategy for students.

In the design step, we should determine the tools and media used for learning. The ESI school provided two tools for distance learning: an LMS (Moodle) and a video conferencing system (MS Teams). Moodle is used to manage learning content, and MS Teams to communicate with students in synchronous mode. In a previous study [24], students suggested using YouTube videos as learning media. YouTube videos help explain complicated concepts [25].

Regarding the instructional strategy, the FL was selected. The study concerned technical courses intended for large classes and taught in a full distance model. The FL approach showed its effectiveness in similar contexts.

\section{Development}

As we chose FL as an instructional strategy and regarding the fact that all the courses had to be taught in full distance learning, we proposed synchronous and asynchronous activities (Fig. 10). Synchronous activities were completed during MS teams' meetings, while asynchronous ones were realized by students, outside online meetings, and following their paces. Before attending online lives, students were invited to consult PPT presentations available on Moodle platform. Some YouTube videos were also added to give more explanations about complicated concepts. An MS teams' meeting was then started with a summary of the learning resources related to this particular meeting. After the summary, the author answered students' questions. If a question required further thought, a Moodle forum was then created to discuss it. Problems were also proposed to students to apply learned concepts. They could discuss their solutions with their classmates in online sessions. The teacher moderated the discussion and helped in case of difficulties. Working within a group to realize a project was possible only for the last-year students. Indeed, their relatively low number and the nature of their courses facilitated using project-based learning.

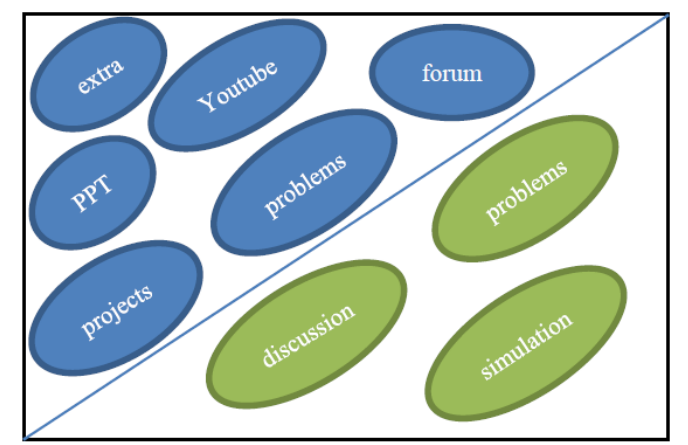

Fig. 10. Synchronous (in green) and asynchronous (in blue) activities.

TABLE I. EXAMPLES OF EXTRAS ACTIVITIES

\begin{tabular}{ll}
\hline \hline Education level & \multicolumn{2}{c}{ Examples of extras activities } \\
\hline Last year & - Recording a simulation for the first Corba lab. \\
& Managing a workshop for a Hadoop \\
installation in a virtual machine. \\
- A tutorial for the creation of a basic SQLite \\
application. \\
- A benchmark of the national and the \\
international mobile app development job \\
market. \\
\hline First year \\
- Recording a simulation for the first Assembly \\
lab. \\
A presentation about Windows and UNIX file \\
systems.
\end{tabular}

In the development stage, almost all issues encountered in the analysis step were fixed:

- All explanations given in the live sessions were added to the learning resources. Youtube videos and simulations recorded by students were also used to guarantee the learning although Internet access issues.

- Students were encouraged to work in a group to solve problems or realizing their projects or extras activities.

\section{Implementation}

Learning resources were gradually uploaded in the Moodle platform, depending on the courses' schedules (Fig. 11).

\begin{tabular}{|c|c|c|c|c|c|}
\hline $19 / 10 / 20$ & $2 / 11 / 20$ & $23 / 11 / 20$ & $7 / 12 / 20$ & $11 / 1 / 21$ & \begin{tabular}{l|l|}
1 & $18 / 1 / 21$ \\
\end{tabular} \\
\hline \multicolumn{6}{|c|}{ Distributed Systems } \\
\hline & \multicolumn{2}{|c|}{ Assembly Language } & & & \\
\hline & & & \multicolumn{2}{|c|}{ Embedded Systems } & \\
\hline & & & \multicolumn{3}{|c|}{ Operating Systems } \\
\hline
\end{tabular}

Fig. 11. Courses' schedules.

Resources prepared by students are also available on the Moodle platform. It was a way to show students that their work is valuable, and the teacher considers them as peers. Fig. 
12 represents the courses' homepage.

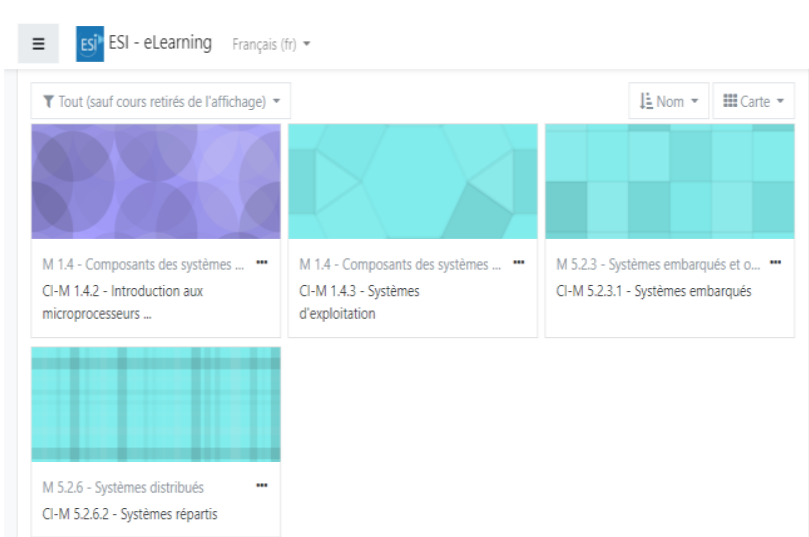

Fig. 12. Courses' homepage.

\section{E. Evaluation}

At the end of the first semester of the academic year 2020-21, first-year students were invited to evaluate both operating systems and assembly language courses. They were 63 students who answered a satisfaction survey composed of seven Likert scale questions and three open-ended questions. The open-ended questions were added to collect students' suggestions on improving the proposed learning system. Results are analyzed in the next section.

\section{RESUlts AND DisCUSSION}

To measure students' satisfaction with the developed courses, we used seven Likert scale questions. Each item was measured using a five-point Likert scale anchored on "strongly agree $=5$ " and "strongly disagree $=1$ ". The satisfaction survey was intended for the first-year students, as they were the most reluctant to distance learning and had no experience. To interpret the quantitative data obtained from the questionnaire, we used descriptive analysis to calculate the mean, the mode, and the standard deviation. The mode represents the score with the highest frequency, and the standard deviation indicates the dispersion of the collected data. A mean score of 3.67 to 5.00 indicates a high level of agreement. A mean of 2.34 to 3.66 shows a moderate level, and values from 1.00 to 2.33 are interpreted as low [26].

We presented the results of the survey in Table II. Overall, students were highly satisfied with both courses Assembly and OS (Q7). For the questions Q1, Q3, and Q5 level of satisfaction can be considered as moderate. Although the mode is 4 , the SD demonstrated that data is relatively dispersed. We turned to the open-ended questions to understand students' feedback on using the MS teams tool and the Moodle platform (Q1 and Q3). These questions invited students to outline the pros and cons of their learning experience. By analyzing them, we also tried to determine why the given learning resources could not help students stay focused on the course (Q5).

In students' responses, internet access issues were frequent. To overcome this problem, they suggested recording the MS Teams' lives. Then, upload the records to the Moodle platform. Some of them also faced issues while installing the necessary tools for labs. Although online solutions for executing labs were proposed, they preferred more support for installing their execution environment locally. Finally, some students judged that new concepts were taught at high speed in the lives, and the teacher had to spend more time explaining.

\begin{tabular}{lllcc}
\multicolumn{5}{c}{ TABLE II: SATISFACTION SURVEY RESULTS } \\
\hline \hline $\mathbf{N}^{\circ}$ & \multicolumn{1}{c}{ Questions } & Mean & Mode & SD \\
\hline Q1 & $\begin{array}{l}\text { How satisfied are you with the } \\
\text { MS Teams sessions? }\end{array}$ & 3.635 & 4 & 0.981 \\
\hline Q2 & $\begin{array}{l}\text { How satisfied are you with the } \\
\text { learning resources given in the } \\
\text { both courses Assembly and OS? }\end{array}$ & 3.889 & 4 & 0.910 \\
\hline Q3 & $\begin{array}{l}\text { How satisfied are you with the use } \\
\text { of the Moodle platform? }\end{array}$ & 3.587 & 4 & 1.204 \\
\hline Q4 & $\begin{array}{l}\text { How satisfied are you with the } \\
\text { support given by the teacher? }\end{array}$ & 4.016 & 4 & 0.934 \\
\hline Q5 & $\begin{array}{l}\text { Do learning resources enable you } \\
\text { to stay focused on the course and } \\
\text { overcome technical issues? }\end{array}$ & 3.556 & 4 & 1.051 \\
\hline Q6 $\begin{array}{l}\text { Do learning activities enable you } \\
\text { to interact with your peers and } \\
\text { work as a group? }\end{array}$ & 3.873 & 4 & 1.046 \\
\hline Q7 $\begin{array}{l}\text { Overall, how satisfied are you } \\
\text { with the both courses Assembly } \\
\text { and OS? }\end{array}$ & 3.778 & 4 & 0.967 \\
\hline \hline
\end{tabular}

On the other hand, students appreciated working in a group for problem-solving and being involved in developing courses' materials. They also liked the FL approach, as they could consult learning resources before the lives. Most students founded the topics interesting as they helped them acquire computer skills. They also outlined that the teacher's efforts to make topics simple helped them to understand better. Finally, the teacher's empathy was considered an essential success factor for both courses. A student said: "I appreciate that our teacher considers our technical issues and does not neglect them, she gets involved in offering us solutions, and I like her way of simply explain topics."

In March 2021, the ESI school organized a workshop entitled "Engineering schools in the covid-19 era: feedback after one year of distance learning". the workshop aims to gather experiences and good practices from professors representing different Moroccan engineering schools. Seven schools participated: EHTP, ENSAK, ENSIAS, EMI, INPT, INSEA, and MINES-RABAT. Participants discussed three axes: tools used, pedagogy adopted, and difficulties encountered by professors and students. Concerning tools, all the schools have used Moodle as an LMS. Some of them acquired equipment such as cameras to help teachers recording high-quality videos for online courses. Engineering schools were more oriented to locally develop their learning materials than using online learning platforms such as Coursera or Udemy. In addition to Moodle, engineering schools selected some video conferencing services to communicate synchronously with students. The MS Teams tool was the most adopted one. The participants agreed that traditional learning strategies such as lectures should be replaced by active learning, requiring more responsibility and engagement from students. They also suggested using projects for learning and also for assessment. Finally, engineering students from all the schools have faced internet access issues. Some of them in rural areas did not even have electricity. Others from low-income families can 
not create a private space at home where to attend courses without interruptions. The EHTP school tried to support students by offering them free internet subscriptions. The ENSIAS school adopted the same measure and proposed free laptop rental for students in need. Although professors appreciated distance learning as it facilitates communication with students in large classes and enables the shy ones to express themselves, they all miss the face-to-face interactions and found it difficult to adapt their courses to distance learning, especially in topics that require practice.

The workshop was an opportunity to compare what we have done in the current study with other Moroccan engineering schools' experiences. Although we faced the same problems and used the same tools, our approach, which consists of co-creating courses with students within an FL strategy, seems innovative and enables students to be more satisfied with their learning.

\section{CONCLUSION}

The study aims to improve students' satisfaction with their learning experience by involving them in the course design process. The course design was based on the ADDIE method and the FL instructional strategy. Results show that students were overall satisfied with the courses included in the study. They particularly appreciated the teacher's support and her understanding of the technical issues they had to struggle to continue learning. Nonetheless, the Moroccan government should be more invested in supporting distance learning and must guarantee necessary material and reliable Internet access for all the students.

\section{CONFLICT OF INTEREST}

The authors declare no conflict of interest.

\section{ACKNOWLEDGMENT}

The author would like to thank the ESI director and all the students who enrich the courses with their valuable contributions.

\section{REFERENCES}

[1] E. Dong, H. Du, and L. Gardner, "An interactive web-based dashboard to track COVID-19 in real time," The Lancet Infectious Diseases, vol. 20, no. 5, pp. 533-534, 2020.

[2] H. Noprisson, "A survey of the online learning implementation during COVID-19 outbreak," International Journal of Recent Contributions from Engineering, Science \& IT (iJES), vol. 8, no. 4, pp. 18-27, 2020.

[3] Morocco's COVID-19 official website. [Online]. Available: http://www.covidmaroc.ma/Pages/LESINFOAR.aspx

[4] T. Priatna, D. S. Maylawati, S. Sugilar, and M. A. Ramdhani, "Key success factors of e-learning implementation in higher education," International Journal of Emerging Technologies in Learning (iJET), vol. 15, no. 17, pp. 101-114, 2020.

[5] M. Sadikin, R. Yusuf, and D. A. Rifai, "Load balancing clustering on moodle LMS to overcome performance issue of e-learning system," Telkomnika (Telecommunication Comput. Electron. Control.), vol. 17, no. 1, pp. 131-138, 2019

[6] J. Deighton, S. T. Lereya, P. Casey, P. Patalay, N. Humphrey, and M. Wolpert, "Prevalence of mental health problems in schools: Poverty and other risk factors among 28000 adolescents in England," The British Journal of Psychiatry, vol. 215, no. 3, pp. 565-567, 2019.

[7] M. E. Loades, E. Chatburn, N. Higson-Sweeney, S. Reynolds, R. Shafran, A. Brigden, and E. Crawley, "Rapid systematic review: The impact of social isolation and loneliness on the mental health of children and adolescents in the context of COVID-19," Journal of the American Academy of Child \& Adolescent Psychiatry, vol. 59, no. 11, pp. 1218-1239.e3, November 2020.

[8] W. Cao, Z. Fang, G. Hou, M. Han, X. Xu, J. Dong, and J. Zheng, "The psychological impact of the COVID-19 epidemic on college students in China," Psychiatry Research, vol. 287, 112934, May 2020.

[9] E. Karasmanaki and G. Tsantopoulos, "Impacts of social distancing during COVID-19 pandemic on the daily life of forestry students," Children and Youth Services Review, vol. 120, 105781, January 2021.

[10] G. Paquette, Instructional Engineering for Network-Based Learning, Pfeiffer/Wiley Publishing Co, 2003.

[11] C. Berger and R. Kam, Definitions of Instructional Design.

[12] H. H. R. Azami and R. Ibrahim, "Development and evaluation of massive open online course (MOOC) as a supplementary learning tool: An initial study," International Journal of Advanced Computer Science and Applications, vol. 10, no. 7, 2019.

[13] G. Sahakian, C. Buléon, and G. Alinier, "Chapter 14 - Educational foundations of instructional design applied to simulation-based education," Clinical Simulation (Second Edition), Academic Press, 2019, pp. 185-206.

[14] J. P. Pernin and A. Lejeune, "Dispositifs d'apprentissage instrumentés par les technologies: Vers une ingénierie centrée sur les scénarios," Actes du colloque TICE 2004, Compiègne, pp. 407-414.

[15] E. Villiot-Leclercq and J. P. Pernin, "Scénarios: repréSentations et usages," Actes du colloque Jocair, 2006, pp. 357-371.

[16] J. P. Pernin and V. Emin, "Evaluation des pratiques de scénarisation de situations d'apprentissage: Une première étude," Actes du colloque TICE Méditerranée, 2006, Genova, Italie.

[17] P. Strelan, A. Osborn, and E. Palmer, "The flipped classroom: A meta-analysis of effects on student performance across disciplines and education levels," Educational Research Review, vol. 30, 100314, June 2020 .

[18] J. W. Baker, "The "classroom flip": Using web course management tools to become the guide by the side," in Proc. the 11th International Conference on College Teaching and Learning, Jacksonville, FL, 2000.

[19] S. Kotabagic et al., "Enhanced learning experience by comparative investigation of pedagogical approach: Flipped classroom," Procedia Computer Science, vol. 172, 2020, pp. 22-27.

[20] S. Bhat, R. Raju, S. Bhat, and R. D'Souza, "Redefining quality in engineering education through the flipped classroom model," Procedia Computer Science, vol. 172, pp. 906-914, 2020.

[21] J. A. Gómez-Tejedor, A. Vidaurre, I. Tort-Ausina et al., "Effectiveness of flip teaching on engineering students' performance in the physics lab," Computers \& Education, vol. 144, 103708, January 2020.

[22] M. M. H. Ahmed and B. Indurkhya, "Investigating cognitive holding power and equity in the flipped classroom," Heliyon, vol. 6, e04672, August 2020.

[23] E. Fiske and H. Ladd, "Elusive equity education reform in post-apartheid South Africa," Brookings Institution Press, Washington DC, 2004.

[24] I. Ryane and N. Faddouli, "A case study of using Edmodo to enhance computer science learning for engineering students." International Journal of Emerging Technologies in Learning (iJET), vol. 15, no. 3 , pp. 62-73, 2020 .

[25] W. M. Jackman, "YouTube usage in the university classroom: An argument for its pedagogical benefits," International Journal of Emerging Technologies in Learning, vol. 14, no. 9, pp. 157-166, 2019.

[26] J. C. Nunnally, Psychometric Theory, New York: McGraw-Hill, 1978.

Copyright (C) 2021 by the authors. This is an open access article distributed under the Creative Commons Attribution License which permits unrestricted use, distribution, and reproduction in any medium, provided the original work is properly cited (CC BY 4.0).

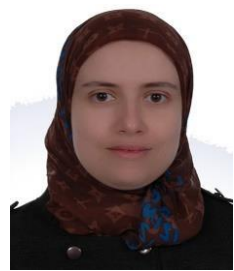

Imane Ryane is an assistant professor at the Schoo of Information Sciences (ESI). She is an engineer from Mohammadia School of Engineering. In 2015 , she completed her $\mathrm{PhD}$ in computer sciences. Before joining the ESI School, she worked for eight years as an IT project manager in a mobile operator. She is passionate about education, and her focuses are distance learning, serious games, active learning, and computer programming. 